\title{
Discussion Paper No. 17-041 \\ Patterns of Entry and Exit in the Deregulated German Interurban Bus Industry
}

Niklas S. Dürr and Kai Hüschelrath

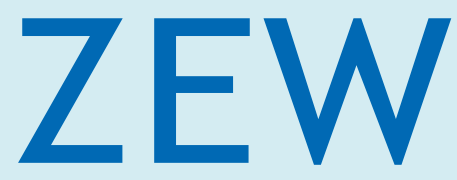

Zentrum für Europäische Wirtschaftsforschung $\mathrm{GmbH}$

Centre for European

Economic Research 


\title{
Discussion Paper No. 17-041 \\ Patterns of Entry and Exit in the Deregulated German Interurban Bus Industry
}

\author{
Niklas S. Dürr and Kai Hüschelrath
}

Download this ZEW Discussion Paper from our ftp server:

http://ftp.zew.de/pub/zew-docs/dp/dp17041.pdf

Die Discussion Papers dienen einer möglichst schnellen Verbreitung von neueren Forschungsarbeiten des ZEW. Die Beiträge liegen in alleiniger Verantwortung der Autoren und stellen nicht notwendigerweise die Meinung des ZEW dar.

Discussion Papers are intended to make results of ZEW research promptly available to other economists in order to encourage discussion and suggestions for revisions. The authors are solely responsible for the contents which do not necessarily represent the opinion of the ZEW. 


\title{
PATTERNS OF ENTRY AND EXIT IN THE DEREGULATED GERMAN INTERURBAN BUS INDUSTRY
}

\author{
Niklas S. Dürr* and Kai Hüschelrath*
}

June 2017

\begin{abstract}
We study patterns of entry and exit in the German interurban bus industry in the first three years after its deregulation in January 2013. Using a comprehensive data set of all firm and route entries and exits, we find that the industry grew much quicker than originally expected with particularly a few new entrants being most successful in quickly extending their route networks from regional to national coverage. Although the clear majority of routes is operated on a monopoly basis, competition does play a key role on routes with a sufficiently large base of (potential) customers. From a spatial perspective, three years after deregulation, the entire interurban bus network connects 60 percent of all 644 larger German cities - with the intensity of entry being dependent on the number of inhabitants, average income, the share of under 24 years old and the presence of intermodal competition by intercity railway services.
\end{abstract}

JEL Class L11, L41, L43, L92, K21, K23

Keywords Deregulation, interurban bus services, entry, exit, competition

* Researcher, Competition and Regulation Research Group, ZEW Centre for European Economic Research and MaCCI Mannheim Centre for Competition and Innovation, Address: P.O. Box 1034 43, D-68034 Mannheim, Germany, E-mail: duerr@zew.de.

* Head, Competition and Regulation Research Group, ZEW Centre for European Economic Research and Director, MaCCI Mannheim Centre for Competition and Innovation, Address: P.O. Box 1034 43, D-68034 Mannheim, Germany, E-mail: hueschelrath@zew.de; Professor, University of Mannheim, L7, 3-5, 68131 Mannheim, Germany; Corresponding author. We are indebted to Rüdiger Knobel (Simplex Mobility) for providing us with his entry and exit data set, two anonymous reviewers for very valuable comments and suggestions as well as to Bettina Chlond and Victoria Urmetzer for excellent research assistance. The usual disclaimer applies. 


\section{Introduction}

The importance of market entry for competition and innovation is mainly twofold. On the one hand, entry plays a crucial role as an equilibrium force in that it competes away excess profits to an equilibrium level ('imitative entry'). On the other hand, entry also plays a creative role in markets, serving as a vehicle for the introduction and diffusion of innovations. Such 'innovative entry' is seen as a disequilibrium force that propels the industry from one equilibrium state to another (see, e.g., Geroski, 1991, 1995, and Hüschelrath and Müller, 2013).

Although market entry is a common occurrence in many industries and markets, recently deregulated industries provide a particularly appealing environment for analyses of entry behavior - first and foremost because the removal of legal barriers to entry is expected to be followed by the development of new business concepts and their application in both existing (incumbent) markets (i.e., imitative entry) and new markets (i.e., innovative entry). Although the study of the effects of such market entries on, e.g., price levels and consumer welfare is certainly of particular interest - reflected in many ex-post studies guided by the seminal contributions of Morrison and Winston (1986) and Kahn (1988, 2003) - a complementary investigation of entry and exit patterns is also likely to contribute to our understanding of competitive processes in recently deregulated industries.

In this context, we take the opportunity of the recently deregulated German interurban bus industry to investigate selected route entry and exit patterns empirically. In particular, studying a selection of (1) basic, (2) competition-related and (3) spatial entry and exit patterns for the first three years after deregulation not only generates important insights on the (aggregated) route entry and exit behavior, but also allows the derivation of a set of conclusions for transport (and competition) policy. Such conclusions might not only be helpful for both politicians and government officials in Germany but are also of relevance for other (European) countries in which the national interurban bus industries were either deregulated recently ${ }^{1}$ or in which the respective governments are currently in the process of implementing the necessary legislative steps.

The remainder of the paper is organized as follows. In the subsequent second section, we initially characterize the process and outcome of the deregulation process in the German interurban bus industry and provide a brief initial overview on firm entry, firm exit and industry growth after deregulation. The third section is then devoted to a detailed

For a characterization of first experiences with the deregulated French interurban bus industry, please see the valuable contribution by Blayac and Bougette (2017). 
characterization of several types of route entry and exit patterns - subdivided further into basic entry and exit patterns, competition-related entry and exit patterns and spatial entry and exit patterns. While descriptive evidence is discussed for all three types of patterns, the particular importance of spatial entry and exit patterns for transport policy demands a complementary econometric investigation of key drivers of the intensity of entry (as measured by the number of destinations and the number of departures per city). The subsequent fourth section introduces into several recent developments in the industry in the year 2016 and discusses important implications for transport and competition policies. The final fifth section summarizes our main results and closes with a brief general assessment of the likely welfare effects of the deregulation of the German interurban bus industry.

\section{Deregulation of the German interurban bus industry}

In this section, we provide an initial characterization of the deregulation of the German interurban bus industry. A brief discussion of the deregulation process in Section 2.1 is followed by an initial overview on operating licenses and firm entry, firm exit and industry growth after deregulation in Section 2.2.

\subsection{The deregulation process at a glance}

Although deregulation processes were initiated in many industries and countries in the last two to three decades, a mixture of public policy arguments and lobbying activities delayed the initiation of such processes in several sectors or industries. For Germany, this description applies to the interurban bus industry. Since 1931, bus companies were only allowed to offer regular interurban bus services - above a travel distance of 50 kilometers - on routes on which the state-owned German rail company Deutsche Bahn AG (or its predecessors) was unable to provide an acceptable service (see also Walter et al. (2011) for further information). Due to the rather dense (interurban) railway network in Germany, the respective law - that aimed at protecting a core business of Deutsche Bahn AG (DBAG) - led to only sporadic interurban bus services ${ }^{2}$ except for routes to/from former West Berlin (operated by Berlin Linien Bus - a subsidiary of DBAG) and international routes (by providers such as Eurolines Germany).

The regulation of the German interurban bus industry remained intact until 2009 when the German government announced plans to deregulate the industry (responding to political pressures from the European Union). In the same year, three students established DeinBus, a

2 The most frequent exceptions were routes connecting inner cities with secondary airports often located in rural areas (without a decent rail connection) such as, e.g., Mannheim to Frankfurt Hahn airport (HHN), a road trip of more than 130 kilometers. 
company that, whenever a sufficiently large number of travelers to a particular destination were found, rented a bus and offered the respective service. Additionally, Deutsche Bahn AG started to operate its own buses under the new IC Bus brand around the same time. Despite several attempts by different lobbying groups to prevent or at least weaken the deregulation of the industry, the German interurban bus industry was fully deregulated in January 2013 - after the respective paragraphs of the Passenger Transport $\mathrm{Act}^{3}$ were changed in the usual legislative (and lobbying) processes (see generally Maertens (2012) and Schiefelbusch (2013) for further information). According to the new §42a Personenbeförderungsgesetz, national scheduled transport with passenger vehicles is allowed for routes above a distance of $50 \mathrm{~km}$ and where no regional rail connection with up to one hour travel time is offered (see $\mathrm{KCW}$ (2014) for more detailed information).

\subsection{Firm entry, firm exit and industry growth after deregulation}

Prior experiences with deregulation processes in transport industries in general (see, e.g., Williams (1993), Morrison and Winston (1986, 1995) or Borenstein and Rose (2007) for the US airline industry) and interurban bus industries in particular (see, e.g., Robbins and White (1986, 2012) for Great Britain or Aarhaug et al. (2012) for Norway) would expect - at the early stages of a deregulated industry - substantial market entry by both new and incumbent firms leading to industry growth through the creation of new lines and routes. As we will show in the following by discussing post-deregulation developments with respect to operating licenses and firm entry, firm exit as well as general industry growth, the deregulated German interurban bus industry follows this general pattern.

\section{Operating licenses and firm entry}

Although the virtual non-existence of scheduled interurban bus services prior to the deregulation of the industry prevents a meaningful comparison of pre- and post-deregulation states, the characterization of selected industry developments since the beginning of the deregulation movement also provides valuable insights. Generally, the full deregulation of the industry in January 2013 led many (potential) providers to apply for an operating license. According to the German Office for Goods Transport (2017, p. 12), the number of licenses increased from 86 in December 2012 to 221 in December 2013, 285 in December 2014 and finally 341 in December 2015 (an overall increase of almost 400 percent).

3 The most important change - leading to the deregulation of the interurban bus industry - referred to $\S 13(2)$ Personenbeförderungsgesetz ('Passenger Transport Act') in which the strict entry regulations were codified. 
In terms of firm entries, i.e., operating license holders that actually decided to offer scheduled passenger transport services with buses, the German Office for Goods Transport (2017, p. 10) reports a rather small growth from 76 firms in 2012 to 97 in 2013, 94 in 2014 and finally 84 firms in 2015. However, despite this only moderate increase in the number of providers, the deregulated environment allowed several new entrants to contribute to a substantial extension of the industry according to measures such as the number of lines or the number of trips. For example, comparing the years 2013 and 2015 reveals an increase in the number of lines from 131 to 299 (i.e., almost 230 percent) and a jump in the average number of weekly trips from 4,714 to 9,018 (an increase of about 190 percent; see German Office for Goods Transport (2017), pp. 14f.).

Briefly introducing the main players in the industry, in addition to the incumbent firm Berlin Linien Bus already mentioned in the preceding section, three new entrants (eventually) turned out to be particularly successful in constructing national interurban bus networks: MeinFernbus, FlixBus and ADAC Postbus. While MeinFernbus started operating - on a small scale though - still in the regulatory era in April 2012, FlixBus and ADAC Postbus commenced their operations in February 2013 and October 2013, respectively. All three new entrants are supported by strong financial investors and follow a subcontractor-type business model in which already existing local bus companies - typically operating in the nonscheduled segment of the bus industry before - agree to offer services under the respective interurban bus brand.

At least in terms of market shares achieved, this strategy has proven successful as in December 2014 - on the basis of the number of offered routes - MeinFernbus was the industry leader with a share of 38.5 percent, followed by FlixBus with 20.8 percent, Berlin Linien Bus with 15.2 percent and ADAC Postbus with 6.1 percent (see German Office for Goods Transport (2017), p. 15). All remaining operators had substantially smaller market shares - partly because they entered the industry at a later point in time but partly also because they either concentrate on the provision of regional services (including airport transfers) or operate on a limited selection of lines with a particularly high (expected) demand.

\section{Firms exits through liquidation and merger}

Although a large number of entries is expected after the deregulation of an industry, a subsequent shakeout period - as part of which the most successful firms will grow further and the less successful firms will exit the industry - appears inevitable. While the first two years after deregulation did not witness any significant events in this respect, the third year not only 
showed two liquidations of smaller players - City2City and PublicExpress - but especially saw the 'mega merger' between the two leading new entrants: MeinFernbus and FlixBus. The two companies announced their merger plans in January 2015 and were - due to their small absolute sizes in terms of turnover ${ }^{4}$ - immediately allowed to start with the implementation of the merger. Although the merged entity announced in fall 2015 that the network reorganization process was finalized, they kept their two separate brands for the entire year 2015 thus allowing us to (partly) still differentiate between the two providers in our empirical analysis below. ${ }^{5}$ However, adding the respective numbers of routes offered by the two merging parties reveals that their joint (route-based) market share increased from 59.3 percent in December 2014 to 72.9 percent in December 2015 (see German Office for Goods Transport (2017), p. 15).

\section{Industry growth and general relevance}

Despite the clear growth trend in the German interurban bus industry in the first three years after deregulation, the overall size of the industry must still be considered as rather small. For example, according to data from the German Federal Statistical Office, about 20 million passengers travelled by scheduled interurban buses in 2015, compared to about 131 million passengers who used long-distance railway services in the same year. ${ }^{6}$ Although the resulting market share of about 13.2 percent for interurban bus services in the market for (surface) long-distance public passenger transportation appears rather small, the pace of industry growth is much higher than originally expected. For example, according to the most recent traffic forecast conducted by a consortium that was commissioned by the German Federal Ministry of Transport and Digital Infrastructure (2014), a passenger growth to about 25 million passengers was expected in the German interurban bus industry until the year $2030-\mathrm{a}$ number that is now expected to be reached in the year 2017 already.

4 According to German merger control legislation, an obligation to notify the German competition authority only exists when the merger exceeds two turnover thresholds: the merging companies must have a combined aggregate worldwide turnover of more than $€ 500$ million and at least one of the companies must have a turnover of more than $€ 25$ million and another of more than $€ 5$ million in Germany.

5 However, as we will show below, we find indications for a substantial reflagging process from one brand to the other already in 2015.

6 See https://www.destatis.de/DE/PresseService/Presse/Pressemitteilungen/2016/02/PD16_052_461.html (last accessed on 14 June 2017) for further information. 


\section{Patterns of route entry and exit in the German interurban bus industry}

In this section, we characterize several types of route entry and exit patterns in the deregulated German interurban bus industry. Based on the characterization of our data set in Section 3.1, we begin in Section 3.2 with a discussion of several basic entry and exit patterns. Subsequent to the presentation of selected competition-related entry and exit patterns in Section 3.3, the third section is closed by providing a spatial perspective on route entry and exit in Section 3.4. Based on the discussion of several descriptive breakdowns of the data, we will particularly investigate key drivers of the intensity of entry - as measured by the number of destinations and the number of departures per city - in an econometric framework.

\subsection{Characterization of the data set}

Our main entry and exit data set was provided by Simplex Mobility and consists of all route ${ }^{7}$ entries and exits of all interurban bus providers in Germany from the beginning of the deregulation era in January 2013 to the end of the third year of deregulation in December 2015. In sum, the raw data set consists of 6,497 routes which have been gradually entered (or populated at least once) by 28 different providers: the incumbent Berlin Linien Bus, the (eventually) two industry leaders MeinFernbus (MFB) and FlixBus (FB), ADAC Postbus as further larger new entrant with a national route coverage as well as 24 other providers consisting of 13 smaller providers and 11 regional providers ${ }^{8}$ - resulting in a balanced panel data set for the first 36 months of the industry. Furthermore, for our spatial analysis below, we have collected additional data - obtained from the Federal Statistical Office of Germany and the Federal Office for Building and Regional Planning - to be able to construct the respective spatial structure, demographic and mode characteristics variables. Last but not least, road distances between the respective origin and destination city centers were retrieved from Google Maps.

\subsection{Basic route entry and exit patterns}

In this section, we present and discuss several basic route entry and exit patterns. Subsequent to a discussion of the number of served routes over time - in total and split between the

7 In the remainder of this paper, a line is defined as an offered regular (scheduled) service from a particular departure city to a particular arrival city, for example, from Hamburg to Munich. A line usually contains several stops, that is, passengers are able to board the bus at a later city and/or get off the bus at an earlier city than the final destination. We therefore define each combination between two different stops on a line as route, that is, if a line has $N$ stops, the number of routes is $\sum_{i=1}^{N-1} i$. The route is our unit of observation and analysis in both the descriptive and the econometric approach. Although a line-based analysis would also be desirable, data limitations prevented an implementation in this paper.

8 The group of 'smaller providers' mostly offers services on a small selection of lines connecting urban areas (as well as international services) while the group of 'regional providers' typically provides specific regional services (e.g., transfers to secondary airports). 
largest providers - as absolute measure of entry activity, we subsequently present and discuss frequency-based market shares as important relative measure of market presence. We close the section with a brief analysis of combined route entry and exit patterns.

\section{Number of served routes}

A suitable starting point for an assessment of entry and exit patterns is the absolute number of route-level entries in the first three years after deregulation. Figure 1 therefore shows the number of served routes of all providers in the German interurban bus industry on the monthly level from January 2013 to December 2015.

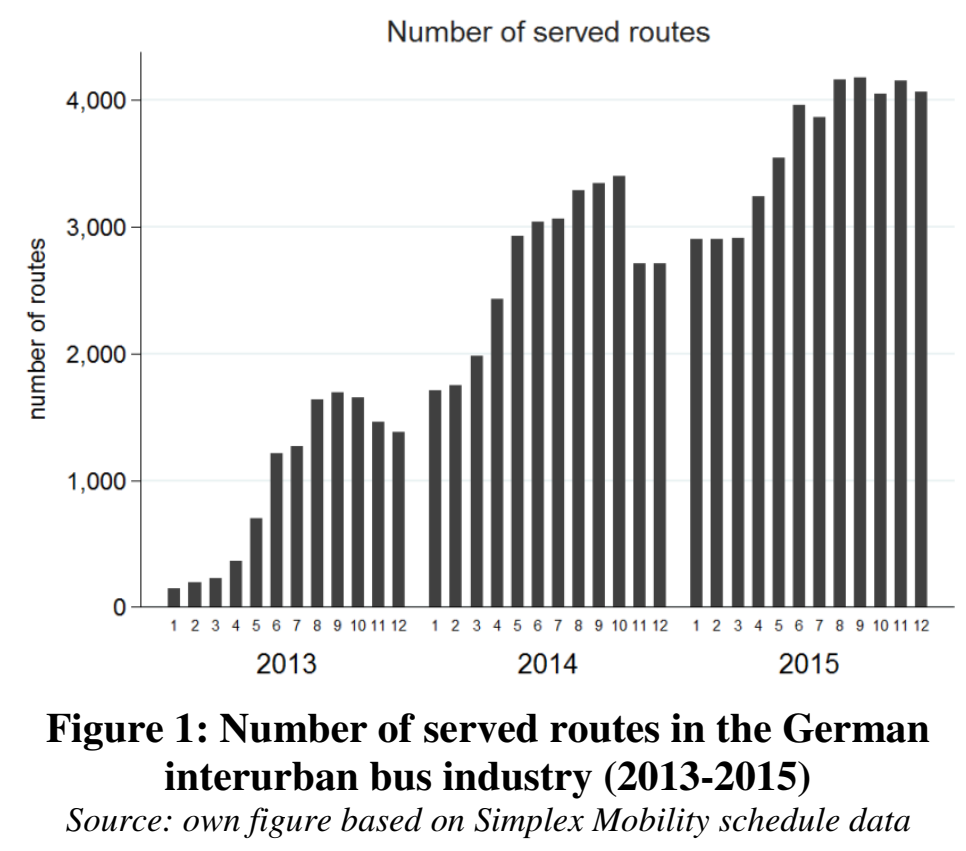

As revealed by Figure 1, the industry experienced an impressive general growth in the number of served routes. Beginning from 146 routes in January 2013, the aggregated entry activity of all providers led to an overall network consisting of 2,716 routes in December 2014 - an increase of a magnitude of 19 - and a further rise of about 50 percent to in sum 4,065 routes in December 2015.

Additionally, Figure 1 suggests a certain seasonality in entry (and exit) activity with a higher number of route entries in the spring and the summer and a lower (or even negative) increase in the number of served routes in the fall and winter months. This is particularly obvious in the second year after deregulation were a larger number of (partly permanent, partly only temporary) route exits by several providers led to a clear decrease in the number of served routes.

Turning from an analysis of aggregated entry and exit activity of all providers to a more detailed analysis of particularly larger providers, the industry can generally be separated into 
one incumbent (Berlin Linien Bus), three (eventually larger) new entrants (MeinFernbus, FlixBus and ADAC Postbus) that started constructing nation-wide networks in the first two years after deregulation, and smaller other providers (serving either specific regional services or operating a small selection of lines connecting urban areas). Aiming at comparing the entry (and exit) behavior of the largest providers in greater detail, Figure 2 shows the number of routes for largest interurban bus providers as well as the group of other providers.

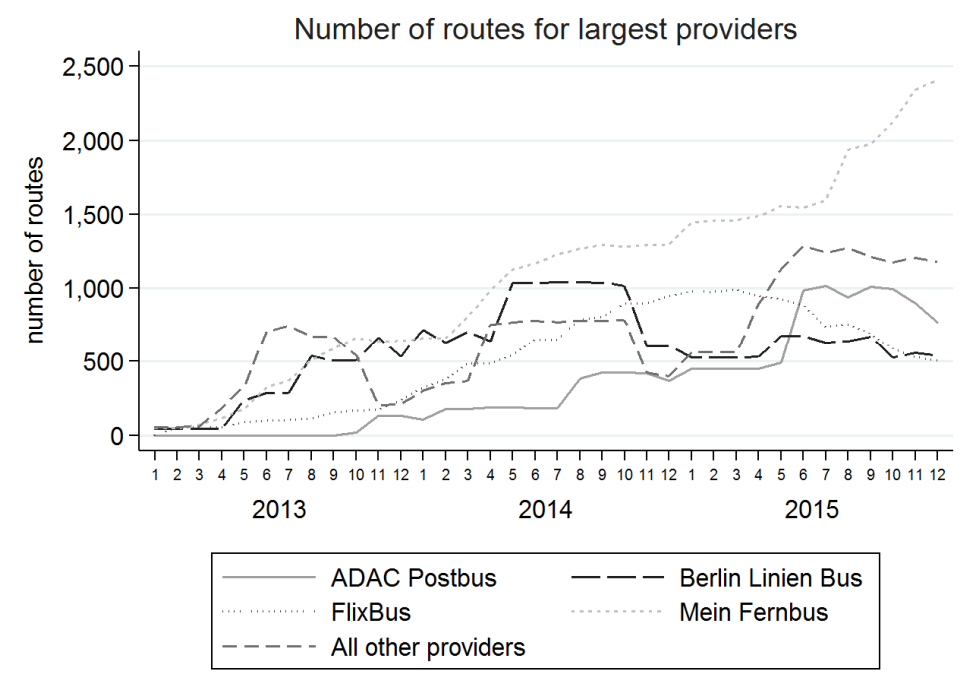

Figure 2: Number of routes for largest interurban bus providers (2013-2015) Source: own figure based on Simplex Mobility schedule data

As shown in Figure 2, the first year after deregulation experienced a substantial growth in the entry activities of particularly Berlin Linien Bus and MeinFernbus. While the former company had substantial prior experiences in operating bus services from the regulatory era, also MeinFernbus started operating - on a small scale though - still in the regulatory era in April 2012. FlixBus and ADAC Postbus, however, commenced their operations in February 2013 and October 2013, respectively, providing a straightforward explanation for their smaller numbers of served routes in the first year of our observation period.

For 2014 - the second year after deregulation - Figure 2 above reveals a further substantial increase in the number of served routes, particularly driven by elevated entry activities of FlixBus and ADAC Postbus but also fortified by further expansions of Berlin Linien Bus and MeinFernbus. In December 2014, MeinFernbus was the (route-based) industry leader providing services on 1,296 routes (i.e., a share of 36 percent), followed by FlixBus that was present on 947 routes (i.e., a share of 26 percent) and Berlin Linien Bus and ADAC Postbus with 603 and 369 routes (i.e., 17 percent and 10 percent), respectively.

In January 2015, the merger between MeinFernbus and FlixBus was announced. Although both brands continued to exist the entire year, the merged company announced the finalization 
of their network restructuring activities in fall 2015. Consequently, it would likely be incorrect to treat the substantial number of route exists by FlixBus in 2015 as real exits - as they might simply be replaced by a corresponding entry of MeinFernbus (as part of a 'reflagging' process). Additionally, the year 2015 experienced a rather stable number of routes operated by Berlin Linien Bus and a substantial increase by ADAC Postbus in June 2016 - in fact, ADAC Postbus almost doubled the number of routes from 494 routes in May 2016 to 987 routes in June 2016. Although we are unable to provide any further evidence, this by far largest monthly increase in the number of served routes by a single provider in our observation period might have been a reaction to the announcement of the merger of MeinFernbus and FlixBus a few months earlier.

\section{Frequency-based market shares}

So far, our analysis concentrated on the number of routes operated in total and by the largest providers. Although this information provides important insights on the industry - and also allows the calculation of route-based market shares - such a measure would likely be biased as it does not take the frequency of service into account. For example, in a route-based market share calculation, a route on which a small 'other provider' offers a service once per week would be treated equally to a route that is operated by several providers several times per day. Aiming at taking the frequency of service into account, Figure 3 shows the monthly market shares based on the frequency of service. ${ }^{9}$

As shown in Figure 3, apart from very few exceptions in the first couple of months of the deregulation era, MeinFernbus always had the largest market share. While the minimum value was reached in April 2013 with 29 percent, the largest market share of 58 percent was already achieved in October 2013. While FlixBus is found to gain market share particuarly in 2014, Berlin Linien Bus is constantly losing in the same time period. In fact, in December 2014, it remained with a small market share of 7 percent. Furthermore, ADAC Postbus had a small and rather constant market share of on average 8 percent in 2014; however, managed to increase it to on average 15 percent in 2015.

\footnotetext{
Although we are confident that frequency-based market shares are a meaningful measure of market concentration, it is important to note that other bases - such as number of passengers or passenger kilometers - appear equally suitable. Although it would have been desirable to compare the respective market share values for different bases, data limitations of our route-level data set unfortunately prevented an implementation in this paper. However, based on experiences in other transport markets (such as airlines, see, e.g., Hüschelrath and Müller (2013)), the differences between different market share bases are expected to be small. We are grateful to an anonymous reviewer for pointing this out to us.
} 


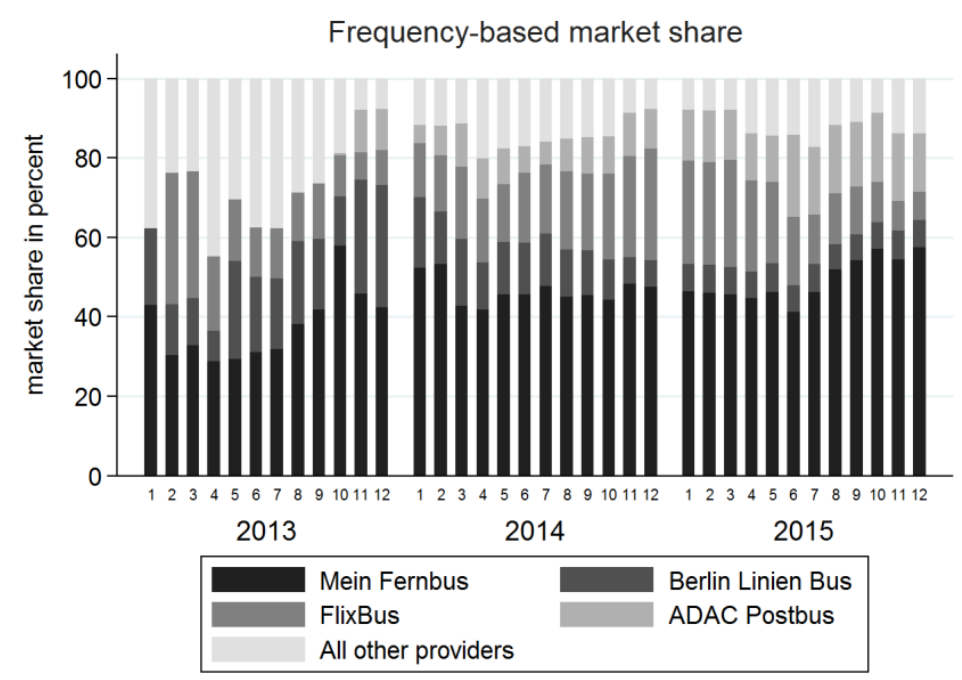

Figure 3: Market shares (frequency-based) in the German interurban bus industry (2013-2015)

Source: own figure based on Simplex Mobility schedule data

Interestingly, the smaller other providers had a significant market share in the first year after deregulation reaching a maximum value of 45 percent in April 2013. However, in the subsequent two years, they experienced substantial reductions from an average market share of 27 percent in 2013 to 14 percent in 2014 and finally 12 percent in 2015 . Furthermore, comparing the market shares plotted in Figure 3 with the number of routes shown in Figure 2 reveals the expected larger differences. For example, referring to the observations for December 2015, while the group of other providers has a market share of 22 percent in terms of number of served routes, their market share drops to 14 percent when taking the frequency of service as calculation base.

\section{Combined route entry and exit patterns}

Although the main focus of our paper is on route entry patterns, exit patterns are closely related. For example, removing buses from several weakly profitable markets might be necessary to be able to enter other more promising markets. Generally, route exits can have operational reasons - e.g., triggered by a low (seasonal or general) profitability - or might be a consequence of the respective provider's market exit through either liquidation or merger.

Aiming at studying whether route exit waves are complemented by entry waves, Figure 4 below shows the combined route entry and exit activity on a monthly basis. While the positive dark-shaded columns show the respective numbers of route entries, the negative lightershaded columns represent the corresponding monthly exits. The solid line plots the net entry- 
exit effect by simply subtracting the number of exits from the number of entries in the respective months.

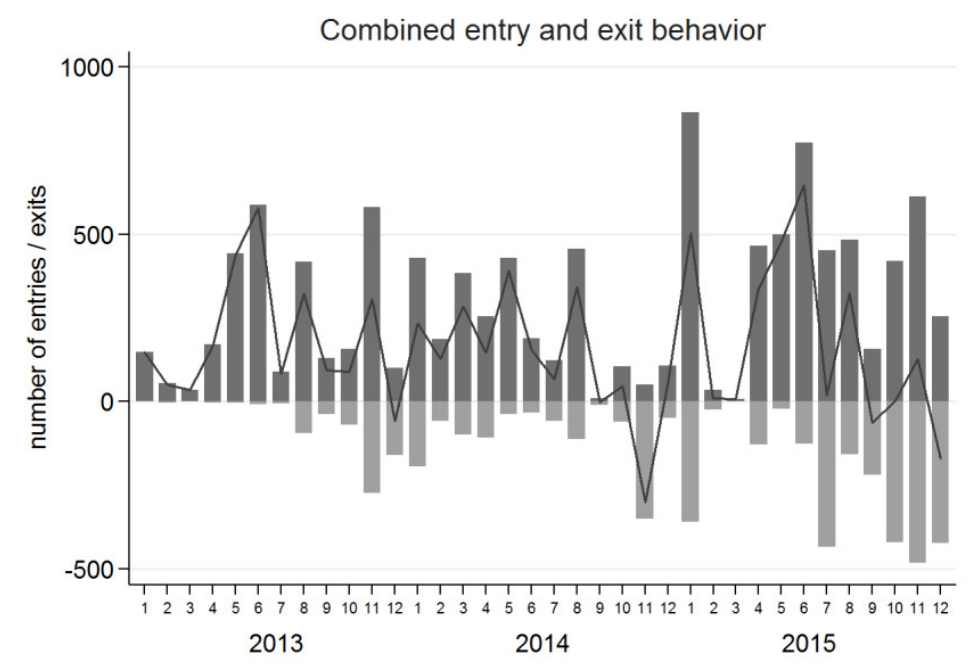

Figure 4: Combined route entry and exit activity (2013-2015)

Source: own figure based on Simplex Mobility schedule data

As revealed by Figure 4, the first few months after deregulation showed a substantial entry activity without any significant route exits. Furthermore, although the fall and winter months in all three years show a significant (partly seasonal) exit activity, the net effect turns negative only on four occasions (with the most recent two months most likely being affected by the merger). In other words, in the clear majority of months, the German interurban bus industry shows a net growth in the number of routes served. In sum, in the pre-merger years 2013 and $2014,5,640$ route entries took place in the German interurban bus industry, compared to 1,830 route exits.

Briefly commenting on the respective entry-exit behavior of the largest providers in the years 2013 and 2014 (not shown in Figure 4), Berlin Linien Bus is found to have the largest number of 1,384 route entries, but also the (by far) largest number of 802 route exits (about 58 percent). Furthermore, MeinFernbus and FlixBus are comparable in the sense that they both show a clearly positive net effect: while FlixBus entered 1,110 routes and left 271 routes in the first two years (about 24 percent), the values for MeinFernbus are 1,526 routes and 292 routes (about 19 percent), respectively. Last but not least, in the year 2014, ADAC Postbus entered 532 routes; however, decided to exit 113 routes (about 21 percent).

\subsection{Competition-related route entry and exit patterns}

Subsequent to the discussion of several basic route entry and exit patterns, we continue in this section with the presentation of selected competition-related entry and exit patterns. Particularly, we will discuss the number of monopoly and competitive routes, entry (and exit) 
into new and existing markets as well as survival rates of entries into new and existing markets.

\section{Number of monopoly and competitive routes}

Although our prior analysis of post-deregulation entry and exit activity provides first important insights into industry developments, a full-fledged description of entry and exit patterns demands a more detailed assessment of especially the relation between monopoly and competitive routes. Building on our initial analysis of the number of routes per provider in the previous section - and under the strong assumption that the German interurban bus industry constitutes an own relevant market ${ }^{10}$ - Figure 5 below plots the number of monopoly and competitive routes between January 2013 and December 2015.

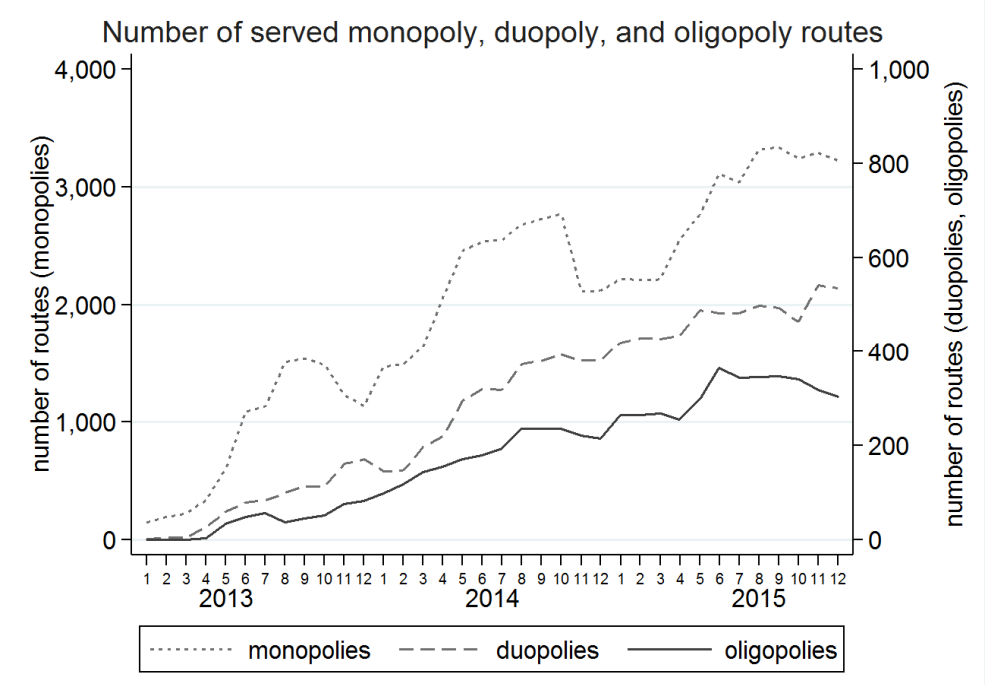

\section{Figure 5: Number of monopoly and competitive routes in the German interurban bus industry (2013-2015) \\ Source: own figure based on Simplex Mobility schedule data}

As shown in Figure 5, the number of monopoly routes follows a clear growth trend - with temporary downward turns in the winter periods of 2013 and 2014 - leading to in sum 2,121 served monopoly routes in December 2014 and 3,227 monopoly routes in December 2015. Interestingly, although the number of competitive routes, i.e., duopoly and oligopoly routes, is much smaller than the number of monopoly routes, their respective developments over time are also mostly increasing; however, they are less volatile and hardly show any seasonal effects. From December 2014 to December 2015, the number of duopoly routes increased from 380 routes to 535 routes; compared to 215 routes and 303 routes for oligopolies.

10 From an antitrust perspective, it is an ex ante open question whether the services provided by the German interurban bus industry constitute an own relevant market or must be considered as a (rather small) fraction of a much larger passenger transportation market (possibly including railway and low cost airline services, car sharing agencies etc.). 
Furthermore, particularly for oligopoly routes, a downward trend can be identified starting in the summer of 2015. As argued before, this trend is most likely be driven by the merger of the two largest providers MeinFernbus and FlixBus and the respective reorganization of their operations. $^{11}$

\section{Entry into new and existing markets}

An interurban bus network is created by multiple route entry decisions by the respective providers. Generally, a profit-maximizing, risk-neutral firm will enter a market if the net present value of expected post-entry profits is greater than the sunk costs of entry. As postentry profits depend on post-entry competition, an entrant operating in a recently deregulated industry therefore has a particular incentive to enter new routes; i.e., routes which are not offered by any competitor at the time of entry.

However, as such entry opportunities are limited - and markets permanently served on a monopoly basis are expected to be rather small in demand and profit (as they would otherwise attract entry) - growth aspirations will force entrants to face competition in the form of entering existing markets. Aiming at studying this mix of two distinct entry strategies entering existing markets and facing competition of incumbent firms and entering new markets - over time for the case of the German interurban bus industry ${ }^{12}$, Figure 6 below plots the aggregated number of entries into new and existing markets for all providers.

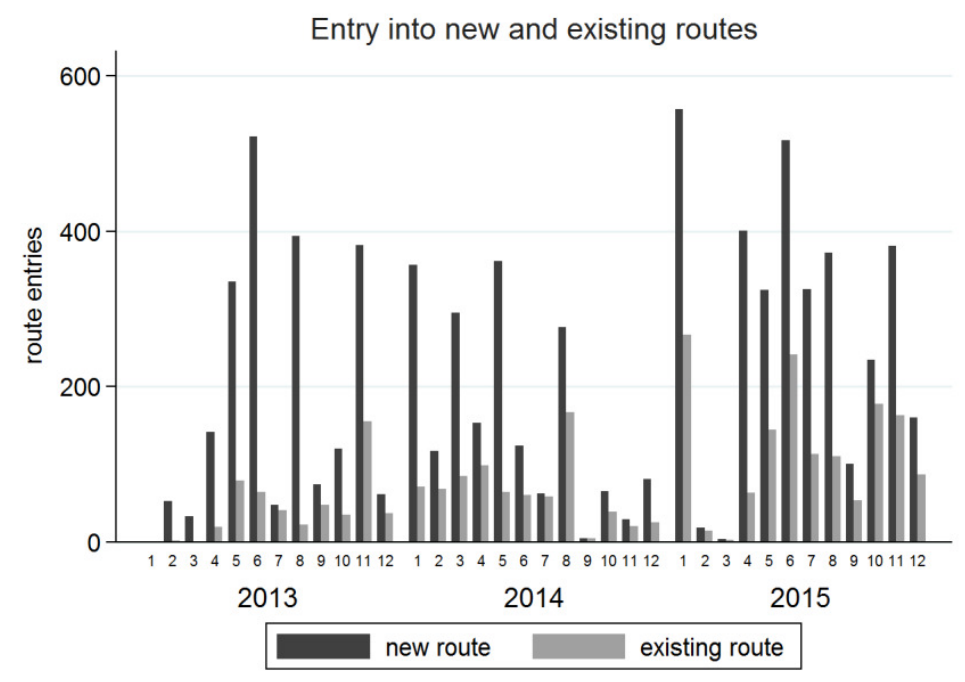

Figure 6: Number of entries into new and existing markets (2013-2015)

Source: own figure based on Simplex Mobility schedule data

As revealed by Figure 6, the number of entries into new markets is indeed substantially higher in all months than the number of entries into existing markets. Over the entire observation

11 For an econometric approach studying the price effects of the merger (ex-ante), see Dürr et al. (2016).

12 For an econometric approach studying the determinants of entry, see Dürr and Hüschelrath (2016). 
period, 7,493 entries took place in new markets compared to only 2,716 entries in existing markets. Comparing the respective yearly averages reveals a particularly large share of about 81 percent for entries into new markets in the first year, while the following two years experience lower but still substantial shares around 70 percent. Although these descriptive findings, ceteris paribus, suggest that competitive pressures in the industry increased over time - due to a higher number of entries into routes in which a competitor is already present the rather young age of the industry apparently still contains many possibilities to grow without the direct confrontation with (a) competitor(s).

Aiming at characterizing entries into new and existing markets a bit further, it was already presumed above that the average market size of new route entries is substantially smaller than for entries into existing markets. Consistent with this claim, we indeed find, for the entire observation period, an average market $\operatorname{size}^{13}$ of $1,235,835$ inhabitants in existing markets compared to only 634,809 inhabitants in new markets. This reminds us of a trade-off known from other transport markets (see, e.g., Hüschelrath and Müller (2014)): while new markets have the advantage of the absence of any competitor, demand and profit expectations are often limited. However, while entries into existing markets come with the burden of competition, potential demand might be substantially higher leading - despite competition to more substantial increases in both absolute profits and consumer welfare than entries into new markets.

\section{Survival rates of entries into new and existing markets}

Even though - according to economic theory - a profit-maximizing, risk-neutral firm will enter a market only if the net present value of expected post-entry profits is greater than the sunk costs of entry; in real markets, these decisions are typically made under incomplete information. For example, after entering a route, the respective entrant might learn that either demand is generally lower than expected and/or further reduced by additional (unexpected) entry of a competitor. In this context, the general success of a firm's entry decisions can be approximated by the calculation of survival rates - defined in our case as the percentages of route entries that are still operated by the respective provider after one year. By that time, we assume that unprofitable entry decisions have been reversed though exit from the respective markets. Based on this general approach, Figure 7 shows the average survival rates of entries into new markets ('innovative entries') and existing markets ('imitative entries') for the years 2013 and 2014.

13 The market size is defined as the sum of the population at the origin and the destination of the respective route. 

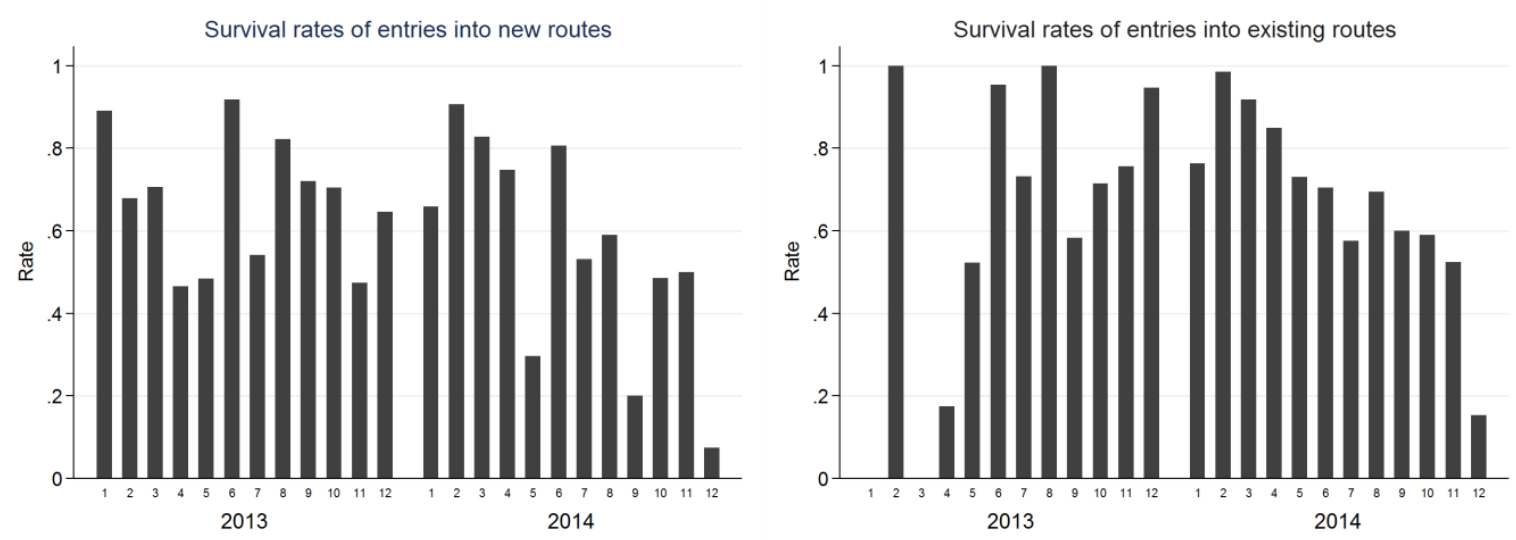

Figure 7: Survival rates of entries into new and existing markets (2013-2014)

Source: own figure based on Simplex Mobility schedule data

As shown by Figure 7, both types of monthly survival rates fluctuate quite substantially. While the aggregated survival rate - i.e., innovative and imitative entries added together experienced a drop from 69.8 percent in 2013 to 64.1 percent in 2014, the split into the two types of entry reveal interesting differences. While innovative entries (plotted in the left-hand chart in Figure 7) show an average rate of 69.2 percent in 2013 compared to 60.1 percent in 2014, the respective rates for imitative entries (plotted in the right-hand chart in Figure 7) are 72.2 percent in 2013 compared to 73.8 percent in the year 2014. As argued above, one possible explanation for this pattern is that firms originally entered the most profitable new markets in 2013 and subsequently added more and more imitative markets (as the options for promising entries into new markets were shrinking). In fact, the reduced attractiveness of (later) entries into new markets is also reflected in the lower survival rate of entries into such markets in 2014 compared to 2013.

Furthermore, in addition to an aggregated analysis of survival rates, it adds value to discuss a split into the largest providers. Such a breakdown particularly allows differentiating between rather successful and rather unsuccessful providers. Limiting our discussion to the respective yearly averages, we find that MeinFernbus shows - for both years and both types of entry the highest survival rates of 85.6 percent in 2013 and 84.6 percent in 2014. While FlixBus shows substantially lower rates of 69.3 percent and 65.3 percent, respectively, Berlin Linien Bus performs reasonably well in 2013 with a rate of 57.5 percent; however, substantially lost in entry performance in 2014 with a drop to an average rate of 30.4 percent. Due to the late entry of ADAC Postbus in 2013, only the 2014 average survival rate of 59.4 percent is finally worth mentioning. 


\subsection{Spatial route entry and exit patterns}

The key function of public passenger transportation services is bringing a country's citizens closer together. In this section, we therefore provide several important insights on route entry and exit patterns from a spatial perspective. We begin in Section 3.4.1 with a discussion of several descriptive breakdowns of the data before we provide an econometric analysis of drivers of the intensity of entry; i.e., the number of destinations and departures per city, in the first three years after the deregulation of the German interurban bus industry.

\subsubsection{Descriptive analysis}

As part of our initial descriptive analysis of spatial route entry and exit patterns, we concentrate on four main measures. First, we study all route entries with respect to their length in kilometers; i.e., we differentiate between entries into short-, medium-, and long-haul routes. Second, and even more important, we take a closer look at three different measures of entry and its intensity from a city's perspective: a) general presence of an interurban bus service, b) the number of destinations that can be reached directly, and c) the number of departures (i.e., the frequency of service).

Entry into short-, medium-, and long-haul routes

Aiming at studying the spatial dimension of the German interurban bus industry, a good starting point is a split of all route entries according to the length of the respective new route. Figure 8 below therefore shows the respective entries over time for short-haul (51-300 km), medium-haul (301-600 km) and long-haul (over $600 \mathrm{~km})$ routes.

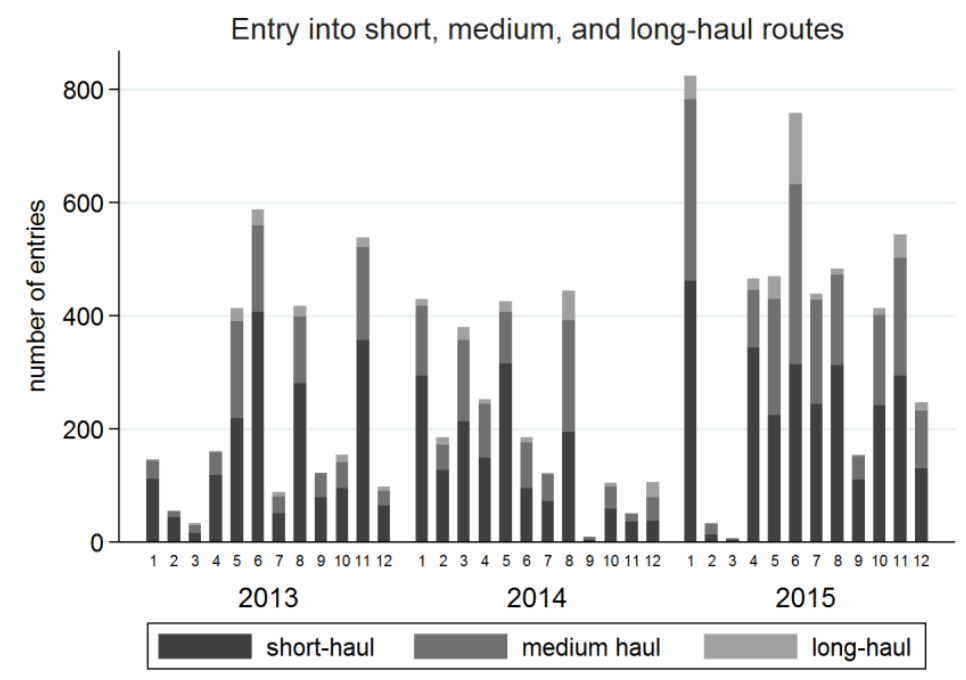

Figure 8: Entries into short-, medium-, and long-haul routes (2013-2015) Source: own figure based on Simplex Mobility schedule data 
As shown in Figure 8, all three types of entry are typically present in the 36 months defining our observation period. In these three years, in sum 6,150 entries took place in short-haul routes, compared to 3,579 entries in medium-haul and 626 entries in long-haul routes. In comparing the three years after deregulation, we find decreasing shares for short-haul entries from 65.6 percent in 2013, to 59.4 percent in 2014 to finally 55.8 percent, while the shares for medium- and (long) haul entries increased from 29.9 (4.5) percent in 2013 and 34.1 (6.5) percent in 2014 to 37.5 (6.7) percent in 2015. Ceteris paribus, these findings suggest that providers first concentrated on the construction of their short- and medium-haul segments and later decided to intensify their - logistically more challenging - long-haul connections. ${ }^{14}$

\section{General presence and intensity of entry}

Although our initial analysis of route entries with respect to length provided first important insights from a spatial perspective, the (quantitative) quality or attractiveness of the respective service from a city's perspective is likely to depend on a) the general presence of the service, b) the number of destinations directly reachable, and c) the number of departures in a given time period. In this respect, Figure 9 below plots descriptive information for the three measures at the very end of our observation period in December 2015.

Starting with the general presence of interurban bus services in Germany, the left-hand chart in Figure 9 shows that interurban bus services are available across the entire country in December 2015. Although parts of Eastern Germany as well as certain areas in the north or the west only show limited access to the network, a straightforward explanation is that the respective unserved regions are rather rural areas with a low population density - thus providing only limited incentives for interurban bus operators to include the respective smaller cities into their networks. In sum, in December 2015, 389 cities out of the group of all 644 larger German cities with more than 20,000 inhabitants had access to the interurban bus network; i.e., 60 percent of all larger German cities had at least one scheduled interurban bus service per week.

14 On the provider level - and again considering the entire observation period - ADAC Postbus shows the longest average length of all route entries with 360 kilometers (not corrected for frequency), followed by FlixBus (297 kilometer), MeinFernbus (287 kilometer) and Berlin Linien Bus (230 kilometers). 
a) Presence

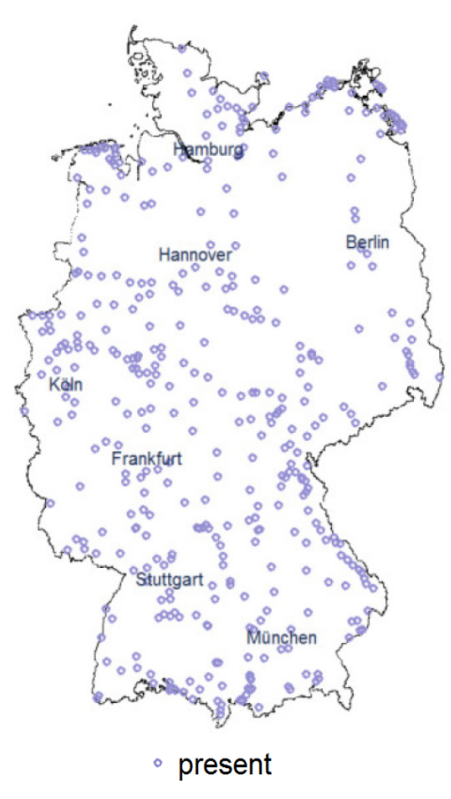

b) Destinations

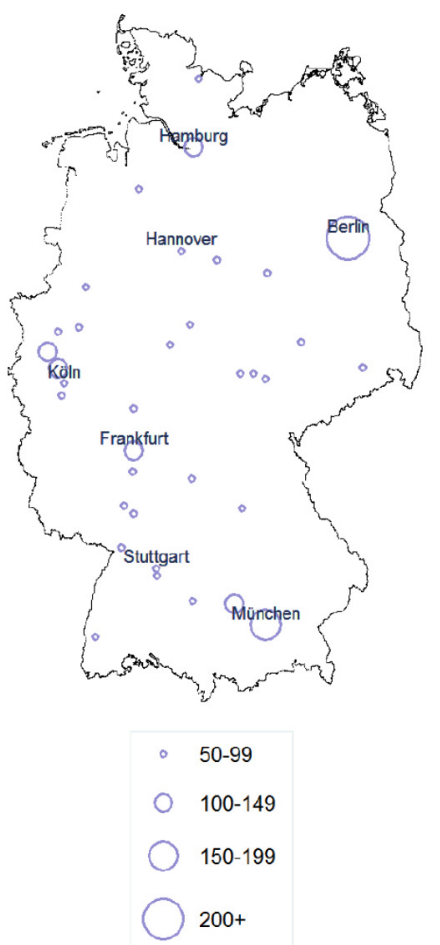

c) Departures

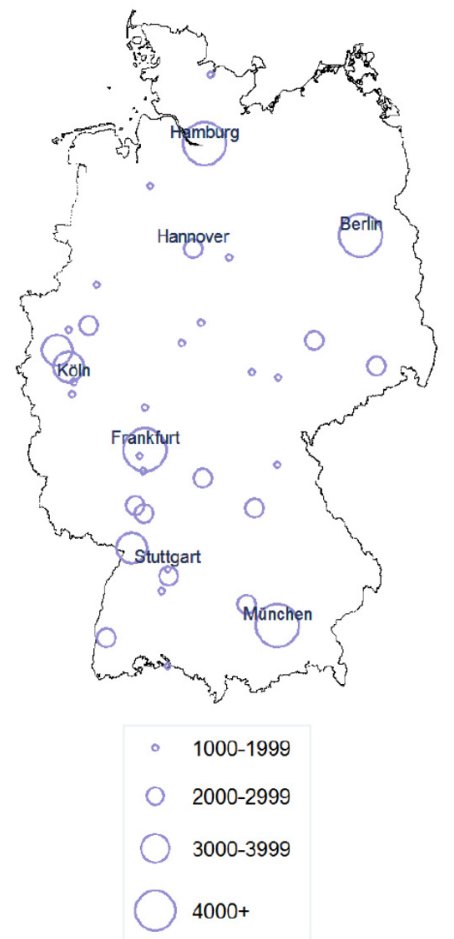

Figure 9: General presence and intensity of entry in December 2015 Source: own figure based on Simplex Mobility schedule data

In addition to the general presence of the service, the number of destinations directly reachable from a city is a key additional quality measure. In this respect, the middle chart shows all cities in Germany from which at least 50 destinations can be reached with a direct trip. While only Berlin (295 cities) offers direct trips to more than 200 cities, Munich (164 cities), Frankfurt (138 cities), Cologne ${ }^{15}$ (129 cities) and Hamburg (109 cities) are also providing very high quality access to interurban bus services. In sum, 35 German cities enjoyed access to more than 50 cities by a direct scheduled interurban bus services in December 2015; including smaller cities in less densely populated areas such as Weimar, Ulm or Gießen.

The second measure of the intensity of entry focuses on the number of departures. In this respect, the right-hand chart in Figure 9 shows all cities with more than 1,000 weekly trips. Unsurprisingly, the large cities Berlin (10,310 departures), Munich (6,553 departures), Frankfurt (5,646 departures) and Hamburg (4,166 departures) again show very large numbers of weekly departures all reaching values beyond $4,000 .{ }^{16}$ In sum, we find that 36 German

15 Please note that the value reported for Cologne refers to October 2015, as the City of Cologne decided at the end of this month to ban interurban buses from the inner city until further notice. Several providers reacted to this order by diverting traffic to the nearby City of Leverkusen.

16 In terms of frequency-based city market shares of the four main providers, the respective values for Berlin/Munich/Frankfurt/Hamburg in December 2014 - i.e., before the MeinFernbus-FlixBus merger - were 
cities have access to a higher quality bus network offering at least 1,000 weekly scheduled trips.

\subsubsection{Econometric analysis of determinants of the intensity of entry}

In this section, we complement our descriptive evidence on spatial entry patterns with an econometric analysis. In particular, given the relevance of the number of weekly destinations and weekly departures as quality measures, we aim at identifying key drivers of an improved presence of such higher quality service. ${ }^{17} \mathrm{We}$ begin with a brief description of our data set and the descriptive statistics in the subsequent section, followed by the specification of our empirical model and our estimation results in the final subsection.

\section{Data set and descriptive statistics}

For our econometric analysis, we use the main route-level entry and exit data set - provided by Simplex Mobility and already characterized in Section 3.1 above - and complement information on our dependent variables (i.e., increases in the number of destinations and the number of departures) with a selection of six demographic and three mode-related characteristics (obtained from the Federal Statistical Office and the Federal Office for Building and Regional Planning) as explanatory variables. Aiming at tackling potential endogeneity issues, all demographic variables are average values from the year 2012 while the mode characteristics variables refer to the year 2013. The descriptive statistics - together with brief definitions of the construction of the respective variables - are presented in Table 1.

as follows: Berlin Linien Bus (13/2/3/3 percent), MeinFernbus (50/51/33/39 percent), FlixBus (27/26/33/37 percent) and ADAC Postbus (6/12/17/12 percent). Please note that the market shares do not add up to 100 percent due to the respective (remaining) market shares of the group of 'other providers'.

17 In an earlier study, Dürr and Hüschelrath (2017) focused on the determinants of the general presence of an interurban bus service in larger German cities. Applying both parametric and semiparametric survival models, they find strong evidence that the probability of a city to be added to a provider's network increases not only with the mere size of its population but also with further demographic characteristics such as average income or the share of young and old inhabitants. Additionally, while an increasing importance of tourism has a further positive effect, a rising automobile density is imposing a significantly negative impact on the probability of a city to gain access to the network. 
Table 1: Descriptive statistics

\begin{tabular}{|c|c|c|c|c|c|c|}
\hline Variable & Description & Mean & Median & $\begin{array}{l}\text { Std. } \\
\text { Dev. }\end{array}$ & Min. & Max. \\
\hline \multicolumn{7}{|l|}{ Dependent variables } \\
\hline Incr Destinations & $\begin{array}{l}\text { Monthly increase of destinations } \\
\text { accessible }\end{array}$ & 0.53 & 2.89 & 0.73 & 0.03 & 8.19 \\
\hline Incr Departures & $\begin{array}{l}\text { Monthly increase of weekly } \\
\text { departures }\end{array}$ & 10.27 & 0.28 & 24.11 & 0.06 & 286.39 \\
\hline \multicolumn{7}{|c|}{ Demographic variables } \\
\hline Population & Overall population in 000 & 79.42 & 20.50 & 229.18 & 0.12 & $\begin{array}{l}3,326.0 \\
0\end{array}$ \\
\hline Income & Average income in '000 & 20.12 & 20.13 & 2.56 & 15.78 & 39.52 \\
\hline Under 24 years & Share of pop. under 24 years & 7.88 & 7.90 & 1.42 & 5.00 & 13.50 \\
\hline Over 65 years & Share of pop. over 65 years & 21.49 & 21.10 & 2.34 & 16.00 & 27.20 \\
\hline Higher education & Share of pop. with A levels & 31.11 & 28.60 & 8.98 & 14.90 & 65.20 \\
\hline Tourism & No. of overnight stays per inhabit. & 9.73 & 5.10 & 10.50 & 0.50 & 42.90 \\
\hline \multicolumn{7}{|c|}{ Mode characteristics variables } \\
\hline Motorway distance & Avg. dist. to next motorway, min. & 15.92 & $9.00^{-}$ & 15.44 & 0.00 & 70.00 \\
\hline Automobile density & No. cars per 1000 inhabitants & 554.65 & 570.40 & 55.10 & 340.60 & 715.87 \\
\hline IC rail access & $=1$ if city has intercity rail access & 0.22 & 0.00 & 0.41 & 0.00 & 1.00 \\
\hline
\end{tabular}

Without aiming at providing a detailed discussion of all variables shown in Table 1, it exemplarily reveals that the average monthly increase of destinations accessible is about 0.5 , compared to an average monthly increase of weekly departures of about 10.3 departures. The average city in the network has about 79,400 inhabitants; however, the substantially lower median of only 20,500 inhabitants reflects the clearly right-skewed distribution of German city sizes. The average share of younger inhabitants (about 7.9 percent) is substantially smaller than the corresponding share of older inhabitants (about 21.5 percent). On average, an interurban bus station is located about 16 minutes away from the next motorway, about 555 cars are available (per 1,000 inhabitants) and about 22 percent of all cities connected to the interurban bus network have (higher-speed) intercity rail access on a regular basis.

\section{Econometric model and estimation results}

In answering our main research question, we apply standard OLS models with the logarithm ${ }^{18}$ of the monthly increase in destinations or departures as dependent variables. Table 2 below shows our estimation results.

18 We use the natural logarithms of the two dependent variables to receive a distribution that is closer to a standard normal distribution. 
(1)

In monthly increase destinations
(2)

In monthly increase departures

\begin{tabular}{|c|c|c|}
\hline ln Population & $\begin{array}{c}\mathbf{0 . 1 4 5 7} \\
(0.0375)\end{array}$ & $\begin{array}{l}\mathbf{0 . 1 8 6 1}^{*} \\
(0.0475)\end{array}$ \\
\hline Income & $\begin{array}{l}\mathbf{0 . 0 4 4 6}^{* * *} \\
(0.0184)\end{array}$ & $\begin{array}{c}\mathbf{0 . 0 9 4 8}^{* * * *} \\
(0.0259)\end{array}$ \\
\hline Under 24 years & $\begin{array}{c}\mathbf{0 . 1 9 7 3}^{* * * *} \\
(0.0443)\end{array}$ & $\begin{array}{l}\mathbf{0 . 1 2 5 9}^{* *} \\
(0.0632)\end{array}$ \\
\hline Over 65 years & $\begin{array}{l}-0.0063 \\
(0.0281)\end{array}$ & $\begin{array}{c}0.0283 \\
(0.0379)\end{array}$ \\
\hline Higher education & $\begin{array}{c}0.0026 \\
(0.0061)\end{array}$ & $\begin{array}{c}\mathbf{0 . 0 2 9 4}^{* * * *} \\
(0.0087)\end{array}$ \\
\hline Tourism & $\begin{array}{l}-0.0014 \\
(0.0049)\end{array}$ & $\begin{array}{c}0.0001 \\
(0.0061)\end{array}$ \\
\hline \multicolumn{3}{|c|}{ Mode characteristics variables } \\
\hline Motorway distance & $\begin{array}{l}\mathbf{0 . 0 0 8 7} \\
(0.0037)\end{array}$ & $\begin{array}{l}0.0046 \\
(0.0054)\end{array}$ \\
\hline Automobile density & $\begin{array}{c}0.0002 \\
(0.0012)\end{array}$ & $\begin{array}{l}-0.0015 \\
(0.0016)\end{array}$ \\
\hline IC rail access & $\begin{array}{c}\mathbf{0 . 7 1 7 4}^{\text {******* }} \\
(0.1400)\end{array}$ & $\begin{array}{l}\mathbf{1 . 0 9 0 6}^{* * * *} \\
(0.1757)\end{array}$ \\
\hline Constant & $-4.3904^{\text {* }}$ & $\begin{array}{l}-3.2680^{*} \\
(1.7614)\end{array}$ \\
\hline $\begin{array}{l}\# O b s . \\
R^{2}\end{array}$ & $\begin{array}{c}393 \\
0.3902\end{array}$ & $\begin{array}{c}393 \\
0.4302\end{array}$ \\
\hline
\end{tabular}

As revealed by Table 2, four variables show highly significant and positive effects for both dependent variables. Unsurprisingly, we find that the larger the population and the larger the share of under 24 years old ${ }^{19}$, the larger the monthly increase in both destinations and departures. While a larger population generally provides a larger base of (potential) customers, the young population is known as the most important actual customer group for interurban bus providers (see, e.g., Office for Goods Transport (2017), pp. 44ff.). ${ }^{20}$ In addition to a positive and significant increase in destinations and departures with an increasing income in the respective city, we also find that the presence of an intercity rail access translates into increases of our two dependent variables. This finding suggests that interurban bus providers are aware of the existence and relevance of intermodal competition by intercity railway services - thus deciding to increase the quality of their service in terms of both number of destinations and number of departures if competition by rail is expected to be fiercer.

19 Interestingly, the share of 'over 65 years old' is found to have no significant effect on both the number of destinations and departures. However, as Dürr and Hüschelrath (2017) find a positive and significant effect of this variable on the decision whether to operate a certain route or not, it can be argued that retired people care about the general presence of interurban bus services but do not care much about their frequency (as they might be rather flexible with respect to their allocation of time due to the absence of a regular job).

20 This is partly also reflected in the positive and significant coefficient for 'higher education' (for the increase in the number of monthly departures only). 


\section{Recent developments in the industry and implications for transport and competition policies}

Although our quantitative study of patterns of entry and exit is able to cover the first three years after deregulation (from 2013 to 2015), industry developments in 2016 were quite significant and therefore deserve a separate treatment - including a discussion of their implications for transport and competition policies. Although any discussion of policy implications must necessarily be incomplete - and difficult to generalize due to our focus on the German market - three topics with a presumably high general relevance are particularly worth discussing in the following: (1) the continuation of the industry consolidation process, (2) the provision of sufficient infrastructure capacities and (3) the optimization of the modal split in long-distance public passenger transportation.

\section{Continuation of the industry consolidation process}

The substantial consolidation process in the deregulated industry - commenced at the latest by the announcement of the merger of the two industry leaders MeinFernbus and FlixBus in January 2015 - continued in the year 2016. In particular, in October 2016, the incumbent Berlin Linien Bus ${ }^{21}$ largely exited the industry, followed by the acquisition of ADAC Postbus by MeinFernbus-FlixBus ${ }^{22}$ in November 2016. According to market data by the IGES Institute, these further consolidation events led to a (scheduled kilometer-based) market share of the merged entity slightly above 90 percent in early $2017 .^{23}$

Although these numbers clearly suggest that intra-modal competition is now limited to a rather small number of larger routes, they do not allow the conclusion that competition policy (or even regulatory) actions are currently necessary - or even that the deregulation of the industry should be considered a failure. First, from a supply-side perspective, inter-modal competition with especially long-distance rail services remains fierce and there are clear indications that the main German rail operator Deutsche Bahn AG has recently been successful in increasing the number of long-distance customers again. Second, from a demand-side perspective, the threat of current bus customers to abstain from trips in case of larger price increases are expected to be strong enough to discipline the remaining providers of interurban bus services sufficiently in their pricing behavior. Nevertheless, competition authorities are well advised to observe market developments on a regular basis - and should

21 See http://www.zeit.de/wirtschaft/2016-09/berlinlinienbus-deutsche-bahn-fernbusmarkt-rueckzug-flixbus (last accessed on 14 June 2017).

22 See http://www.zeit.de/wirtschaft/unternehmen/2016-08/fernbus-flixbus-postbus-uebernahme (last accessed on 14 June 2017).

23 See http://www.iges.com/presse/2017/fernbusmarkt-quartal-i/index_ger.html (last accessed on 14 June 2017). 
not hesitate to intervene if there are indications that the German interurban bus industry constitutes an own relevant market and its dominant operator MeinFernbus-FlixBus would therefore have the incentives and the possibilities to abuse its market power in the form of substantially higher prices. ${ }^{24}$

\section{Provision of sufficient infrastructure capacities}

Despite the continuation of the consolidation trend in 2016, the industry continued to grow in terms of passengers carried or number of routes offered - leading to an actual growth substantially higher than originally expected. From a transport policy perspective, this finding particularly suggests that the provision of sufficient infrastructure capacities is crucial for the young industry to grow and to thus maximize its positive contribution to welfare. This conclusion not only applies to the installation or extension of point infrastructures (such as bus terminals) but also includes extensions (or optimizations, respectively) of line infrastructures (such as road capacities in (as well as to/from) the inner cities). The latter aspect has gained in importance recently due to first initiatives by cities - e.g., the large City of Cologne $e^{25}$ - to ban interurban buses from the inner cities due to infrastructure capacity limitations.

\section{Optimization of the modal split in long-distance public passenger transportation}

More generally, the appearance of a new transport mode suggests the question after a reshuffling of the modal split in long-distance public passenger transportation. In particular, given the key aim of transport policy to set the framework conditions for a cost effective and reliable provision of transport services throughout the entire country, the question is raised whether and to what extend interurban buses could replace existing sporadic (and often subsidized) rail connections into less densely populated areas. For the connection of such cities to a long-distance public passenger transportation network, the interurban bus is not only likely to offer a cheaper and more flexible alternative to railway services, but it has already proven that such routes can be operated on a permanent basis without receiving any type of subsidy. From this angle, the deregulation of the interurban bus industry not only generates a substantial and permanent increase in consumer welfare but also provides the

24 It is important to note here that the observation of increasing prices alone would not allow the conclusion that these price increases are necessarily anticompetitive. In the first few years after deregulation, competition was exceptionally fierce and the respective operators were mostly only able to survive through the support of external financial investors. Consequently, in the development towards a longer-term industry equilibrium, price increases are expected and the crucial task for a competition authority is to develop an idea of what percentage price increase is still considered acceptable from a long-term competition perspective. We are grateful to an anonymous reviewer for pointing this out to us.

25 See https://www.flixbus.com/no-bus-traffic-in-the-center-of-cologne (last accessed on 14 June 2017). 
possibility to reduce government spending through a further optimization of the modal split in long-distance public passenger transportation.

\section{Summary and conclusion}

Providing firms with the freedom to decide on route entries and exits is a compulsory part of every serious deregulation movement. Free entry and exit not only allows incumbent firms to reorganize their operations aiming at improving the efficient provision of services, but it also provides opportunities for new firms to enter the industry and test different market concepts and strategies. The most successful firms - i.e., the incumbent(s) and/or the new entrant(s) are expected to grow further while the less successful firms are likely to exit the industry at some point through either liquidation or merger.

In this context, we take the opportunity of the recently deregulated German interurban bus industry to investigate selected route entry and exit patterns empirically. In particular, after studying a selection of (1) basic, (2) competition-related and (3) spatial entry and exit patterns for the first three years after deregulation, we can say - referring to our initial analysis of basic route entry and exit patterns - that entry into the industry (and thus industry growth) was much more substantial than ex-ante expected. For example, in terms of number of passengers transported, the target number of 25 million - that was originally expected for the year 2030 - is now likely to be reached in the year 2017 already. In fact, from the beginning of the deregulation era in January 2013 to the end of the third year in December 2015, the number of served routes increased from 146 to 4,065 (an increase of a magnitude of 28).

A key driver of the quick growth of the industry after deregulation is the subcontractortype business model applied by all larger new entrants; i.e., the providers avoid buying their own fleet but agree on sub-contracts with existing bus companies from the non-scheduled segment of the industry. Furthermore, our descriptive analysis of the number of entries - as well as survival rates of route entries - suggests that the first moving new entrants with a clear and ambitious plan to quickly extend their route networks (and backed by strong external financial investors) gained the highest (frequency-based) market shares in the young industry.

Turning to the key insights from our discussion of competition-related route entry and exit patterns, we observe that the clear majority of route entries took place in new markets in which no competitor was already operating. However, especially routes with a sufficiently large base of (potential) customers - connecting one or two larger cities - turned to competitive routes rather quickly after deregulation. However, the recently observed consolidation trend - particularly caused by the merger between the two industry leaders 
MeinFernbus and FlixBus - has increased market concentration substantially and raises concerns whether competition in the industry might be negatively affected.

Finally, our analysis of spatial route entry and exit patterns reveals that entries originally concentrated particularly on short- and medium-haul routes and were later extended to further medium- and long-haul routes. In sum, 60 percent of all 644 larger German cities above 20,000 inhabitants were connected to the network in December 2015 - with the clear majority having no access to (higher-speed) intercity rail services - while the intensity of entry in terms of number of destinations and departures is found to increase with population, average income, the share of under 24 years old and the presence of intermodal competition by intercity railway services.

In sum, the results of our study on route-level entry and exit activity support the conclusion that the deregulation of the German interurban bus industry is a further example of a successful deregulation of a transport industry. The expected highly positive effects on consumer welfare are driven directly by the achieved clear improvement in the mobility options of price sensitive people living in larger cities - and indirectly by imposing increasing pressures on intermodal competitors such as particularly railway services to improve their product portfolios and to diversify their pricing strategies. Furthermore, prospectively, further extensions of the interurban bus networks through the inclusion of further medium- and smallsized German cities as well as international connections are likely to boost the positive impact of deregulation on consumer welfare further.

\section{References}

Aarhaug, J., N. Fearnley and P. Christiansen (2012), Deregulation of a Long Distance Express Coach Market, Working Paper, Institute of Transport Economics, Oslo.

Blayac, T. and P. Bougette (2017), Should I Go by Bus? The Liberalization of the LongDistance Bus Industry in France, Transport Policy 56, 50-62.

Borenstein, S. and N. Rose (2007), How Airline Markets Work ... Or Do They? Regulatory Reform in the Airline Industry, NBER Working Paper 13452, Cambridge.

Dürr, N. and K. Hüschelrath (2017), Deregulation and the Determinants of Network Access: Evidence from the German Interurban Bus Industry, Applied Economics Letters 24 (13), 950-955.

Dürr, N. and K. Hüschelrath (2016), Deregulation and the Determinants of Entry: Evidence from the German Interurban Bus Industry, ZEW Discussion Paper No. 16-054, Mannheim. 
Dürr, N. and K. Hüschelrath (2015), Competition in the German Interurban Bus Industry: A Snapshot Two Years After Liberalization, Competition and Regulation in Network Industries 16 (3), 188-218.

Dürr, N., S. Heim and K. Hüschelrath (2016), Deregulation, Competition, and Consolidation: The Case of the German Interurban Bus Industry, Journal of Transport Economics and Policy 50 (2), 164-188.

Federal Ministry of Transport and Digital Infrastructure (2014), Verkehrsprognose 2030, Anlage Verkehrsverflechtungsprognose, June 2014, Berlin.

Geroski, P. (1995), What Do We Know about Entry?, International Journal of Industrial Organization 13, 421-440.

Geroski, P. (1991), Market Dynamics and Entry, Oxford.

Hüschelrath, K. and K. Müller (2014), The Value of Bluer Skies: How Much Do Consumers Gain from Entry by JetBlue Airways in Long-Haul U.S. Airline Markets?, International Journal of Transport Economics 41 (1), 131-158.

Hüschelrath, K. and K. Müller (2013), Patterns and Effects of Entry in U.S. Airline Markets, Journal of Industry, Competition and Trade 13, 221-253.

Kahn, A. (2003), Lessons from Deregulation: Telecommunications and Airlines after the Crunch, Washington, DC.

Kahn, A. (1988), The Economics of Regulation: Principles and Institutions, Cambridge.

KCW (2014): New Long-distance Coach Stations and Licensing Practices, Study commissioned by MeinFernbus.de, ADAC Postbus and VDA Verband der Automobilindustrie, Berlin.

Maertens, S. (2012), Buslinienfernverkehr in Deutschland - effiziente Ausgestaltung einer Liberalisierung, Wirtschaftsdienst 2012-8, 554-562.

Morrison, S. and C. Winston (1995), The Evolution of the Airline Industry, Washington D.C.

Morrison, S. and C. Winston (1986), The Economic Effects of Airline Deregulation, Washington D.C.

Office for Goods Transport (2017), Marktbeobachtung Güterverkehr - Marktanalyse des Fernbuslinienverkehrs 2016, Köln.

Robbins, D. and P. White (2012), Long-term Development of Express Coach Services in Britain, Research in Transport Economics 36, 30-38.

Robbins, D. and P. White (1986), The Experience of Express Coach Deregulation in Great Britain, Transportation 13, 359-384. 
Schiefelbusch, M. (2013), Past and Future Regulation of Interurban Coach Services in Germany, Journal of Transport Economics and Policy 47, 299-305.

Walter, M., F. Haunerland and R. Moll (2011), Heavily Regulated, But Promising Prospects: Entry in the German Express Coach Market, Transport Policy 18, 373-381.

Williams, G. (1993), The Airline Industry and the Impact of Deregulation, Cambridge. 